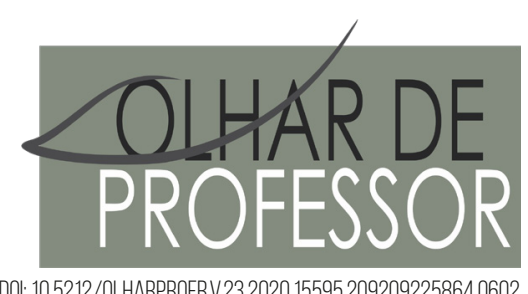

DO: 10.5212/OLHARPROFR.V.23.2020.15595.209209225864.0602

\title{
RELATOS DE EXPERIÊNCIA SOBRE IDENTIDADE ÉTNICA EM UMA ESCOLA INDÍGENA NO ESTADO DE RORAIMA
}

\author{
INFORMES DE EXPERIENCIA SOBRE IDENTIDAD ÉTNICA EN UNA ESCUELA INDÍGENA EN EL \\ ESTADO DE RORAIMA \\ INFORMES DE EXPERIENCIA SOBRE IDENTIDAD ÉTNICA EN UNA ESCUELA INDÍGENA EN EL \\ ESTADO DE RORAIMA
}

\author{
MARY JANE BARRETO DE SOUZA* \\ RAIMUNDA GOMES DA SILVA*
}

\begin{abstract}
Resumo: Este artigo relata uma pesquisa realizada em uma escola indígena. Buscou-se compreender como a identidade étnica permeia a educação escolar indígena, no sentido de entender de que forma é realçada e afirmada nesse âmbito. Como orientação teórica, toma-se a visão de identidade cultural de Stuart Hall (1999), que a percebe enquanto construção social, cultural e histórica, bem como as reflexões de Santos (2016) e Scott (1996). Na revisão teórica sobre educação escolar indígena, temos discussões acerca dos apontamentos de Nascimento (2014), Mato Grosso (1997), Ribeiro (2007), Burbano Paredes (1994), Ferreira (2001) e Freire (2004). A metodologia consiste em um relato de experiência, a partir do diálogo empreendido durante as aulas, somado a uma pesquisa bibliográfica. Os resultados indicam que os materiais didáticos utilizados na escola pesquisada apresentam um "índio" estereotipado. Fato que evidencia a necessidade de os(as) docentes revisitarem a prática e os instrumentos pedagógicos, no sentido de fazer com que as identidades étnicas sejam ressignificadas, demonstrando que o (a) indígena não é apenas aquele ilustrado nos materiais didáticos, mas sujeitos que passam por transformações, dependendo da época, da história e da cultura considerada.
\end{abstract}

Palavras-chave: Educação Escolar Indígena. Identidade Étnica. Makuxi. Wapichana.

\begin{abstract}
This article reports a research in an indigenous school. We sought to understand how the ethnic identity permeates the indigenous school education, and in order to understand in what ways these ethnic identities are highlighted and affirmed. As theoretical orientation the vision of cultural identity of Stuart Hall (10999), view as social and cultural construction, and historical heritage linked to the reflections of Santos (2016) and Scott (1996). In the theoretical review on Indigenous School Education we have discussions about the reflections of Nascimento (2014), Mato Grosso (1997), Ribeiro (2007), Burbano Paredes (1994), Ferreira (2001) and Freire (2004). The methodology is reports of experience by dialogue during school lessons, aggregated to a bibliographic research. The results indicate that the didactic materials used at research school presented a stereotyped "indio" or an "outsider". This impact raised the need of teachers to be attentive and revisit the practice and the pedagogical tools in order so ethnic identities are reframed and that indigenous are not only that that is configured in the didactic material (proven) but also subjects that undergo transformations depending of the season, history and culture.
\end{abstract}

Keywords: Indigenous School Education. Ethnic Identity. Macuxi. Wapichana.

\footnotetext{
* Graduada em História pela Universidade Federal de Roraima; Pós-graduada em História da Amazônia pela Universidade Estadual de Roraima. Mestranda pelo Programa de Pós-graduação em Educação pela Universidade Estadual de Roraima. E-mail: maryjane252011@hotmail.com.

${ }^{* *}$ Professora de História da Universidade Estadual de Roraima - UERR. Doutoranda em História Social pela PUCSP, Mestre em História Social pela UFRJ e Graduada em História pela UFPE. E-mail; silvaraimunda@uerr.edu.br
} 
Resumen: Este artículo reporte sobre la investigación en una escuela indígena. Intentamos comprender cómo la identidad étnica impregna la educación escolar indígena, en el sentido de comprender cómo se resaltan y afirman estas identidades étnicas. Como orientación teórica, la visión de identidad cultural de Stuar Hall (1999) vista como una construcción social, cultural e histórica vinculado a las reflexiones de Santos (2016) y Scott (1996). En la revisión teórica sobre la educación escolar indígena, tenemos discusiones sobre las reflexiones de Nascimento (2014), Mato Grosso (1997), Ribeiro (2007), Burbano Paredes (1994), Ferreira (2001) y Freire (2004). La metodología aborda informes de experiencia a través del diálogo realizado durante las clases, agregado a una investigación bibliográfica. Los resultados indican que los materiales de enseñanza utilizados en la escuela investigada presentan un “indio” estereotipado. Impacto que despertó la necesidad de que los maestros estén atentos para revisar las prácticas e instrumentos pedagógicos y resignificar las identidades étnicas, lo que demuestra que la persona indígena no es solo la que está configurada (se muestra) en los materiales de enseñanza, pero sujetos que experimentan transformaciones, dependiendo del tiempo, la historia y la cultura.

Palabras clave: Educación Escolar Indígena. Identidad Étnica. Makuxi. Wapichana.

\section{INTRODUÇÃO}

A presente pesquisa investiga a identidade étnica de discentes Makuxi e Wapichana no contexto da educação escolar indígena no estado de Roraima. Ela se insere nas reflexões sobre os aspectos de formações (afirmações) identitárias nos processos educacionais escolares em comunidades indígenas.

O interesse em trabalhar a temática indígena foi certamente influenciado por questões subjetivas, pois, como docente indígena da etnia Makuxi, surgiu a ideia de elaborar uma pesquisa acerca da identidade étnica dos povos indígenas na educação escolar. Ser indígena e docente favorece o contato com o tema da pesquisa em educação indígena, dessa forma, contribui para a observação das reflexões presentes no estudo.

O objetivo geral da pesquisa foi analisar como a identidade étnica permeia a educação escolar, tomando como objeto de estudo uma escola estadual de ensino fundamental indígena no estado de Roraima.

Como guia do conceito de identidade optou-se por Stuart Hall, que, ao abordar a identidade na pós-modernidade, afirma que "[...] o sujeito, previamente vivido como tendo uma identidade unificada e estável, está se tornando fragmentado; composto não de uma única, mas de várias identidades, algumas vezes contraditórias ou não resolvidas” (HALL, 1999, p. 12-13). Dentro dessa perspectiva, a identidade "É definida historicamente, e não biologicamente. O sujeito assume identidades diferentes em diferentes momentos, [...] de tal modo que nossas identificações estão sendo continuamente deslocadas” (HALL, 1999, p. 13).

Desse modo, toda leitura relacionada a identidade étnica será vista enquanto construção social, cultural e histórica, em consonância com as reflexões de Tomas Tadeu da Silva (2007), juntamente com Laiana Pereira Santos (2016), que estuda questões referentes à identidade e educação escolar indígena. Além disso, busca-se empreender uma breve discussão sobre gênero e identidade através de Scott (1996). Para as reflexões sobre a educação escolar indígena, são tomados como principais autores Nascimento (2014), Mato Grosso (1997), Ribeiro (2007) e Freire (2004).

Este trabalho aborda uma linha histórica sobre a questão indígena no Brasil desde o período da colonização, sendo possível observar que a educação indígena no país teve início com a chegada dos jesuítas, que estiveram à frente desse processo nos dois primeiros séculos de colonização, de 1549 até 1756. O segundo período identificado se estende de meados do século XVIII a meados do século XX, dividido em duas fases: a fase Pombalina e a fase que compreende o Império, a Primeira República e ditadura Vargas. Em 1910 foi criado o Serviço de Proteção aos Índios (SPI), com o intuito de integrar o índio à sociedade nacional por meio do trabalho. Nesse contexto, a educação tinha como foco preparar o índio para o mercado de trabalho.

A partir de 1970, quando uma série de organizações não governamentais passou a questionar o modelo educacional destinado às populações indígenas, começaram a surgir experiências inovadoras em educação escolar voltada para as suas especificidades. Foi, portanto, a partir dessas experiências que 
se iniciou a construção de propostas curriculares diferenciadas e materiais didáticos específicos para as escolas indígenas, dinâmica que se consagraria juridicamente com a Constituição Federal de 1988.

Dessa maneira, o presente trabalho problematiza de que forma todo esse contexto histórico dos povos indígenas reflete na educação escolar hoje em dia. Além disso, busca-se verificar como os aspectos identitários étnicos são reforçados nos processos educacionais e ambientes indígenas. Investiga-se sobre os aspectos identitários com o intuito de saber por que os discentes indígenas não se reconhecem como indígena, sendo alunos de uma escola indígena que está localizada dentro uma comunidade indígena.

A pesquisa foi realizada com discentes indígenas dos povos Makuxi e Wapichana em uma escola indígena estadual de ensino fundamental no estado de Roraima, na região da Serra da Lua, no município de Cantá, por meio de diálogos e atividades informais durante as aulas, e descrita como um relato de experiência.

Realizou-se um levantamento de dados bibliográficos nas bibliotecas da Universidade Estadual de Roraima e da Universidade Federal de Roraima, bem como de artigos em periódicos online especializados, tais como Revista de Estudos e Pesquisas, da Funai, Revista Brasileira do Caribe, entre outros trabalhos científicos. Foram consultados também acervos particulares e sites de instituições que prezam o rigor acadêmico, para dar embasamento à pesquisa.

Este trabalho se insere entre os estudos realizados em Roraima no campo educacional. Considerando o quão profundo e fértil é a problemática da educação escolar indígena nesse singular lugar da Amazônia, especificamente no estado de Roraima, a pesquisa se faz necessária para que possibilite encontrar caminhos e mostre a possibilidade de pesquisar outras inquietações para lançar luzes sobre as relações culturais, históricas e os aspectos identitários nos processos educacionais em escolas indígenas.

A educação escolar para os povos indígenas no Brasil se iniciou nos primeiros tempos da colonização, surgindo como uma necessidade de escolarização dos indígenas por parte da coroa portuguesa, visando o contato com essa população e, dessa maneira, favorecendo o processo de colonização e apropriação das terras aqui encontradas. Tal processo de educação escolar continuou em 1845, passando para a tutela do governo imperial a catequese e civilização dos índios, por meio do Decreto 246 de 24 de julho, conforme menciona Ferreira (2001). O autor afirma que, na colonização e no período do Império, a finalidade da educação escolar era catequisar e civilizar os indígenas, prosseguindo até o período da República, com a criação do Serviço de Proteção ao Índio (SPI), em 1910, cujo objetivo era a integração do indígena à sociedade.

Essa problemática do contato com os indígenas visando a apropriação de suas terras prevaleceu até décadas atrás, sendo a questão repensada a partir da década de 1970. Nesse período, os povos indígenas no Brasil passaram a reivindicar seus direitos perante o governo nacional, direitos esses que incluíam uma educação diferenciada que respeitasse sua diversidade cultural e suas formas de viver e de pensar (BRASIL, 2007).

Nascimento (2014) observa que as populações indígenas no Brasil, antes da Constituição de 1988, eram tuteladas pelo Estado. A partir de então, passaram a ter seus direitos reconhecidos frente à sociedade, o que favorece a manutenção de suas formas específicas de viver e de pensar, suas línguas, culturas e modos próprios de produção. Direitos esses conquistados através de manifestações sociais por parte de organizações não governamentais, movimentos indígenas e indigenistas surgidos na década de 1970. Como consequência, as populações indígenas atualmente dispõem de um modelo educacional diferenciado, específico, bilíngue e intercultural, vinculado a um currículo que leva em consideração as questões culturais, sociais, econômicas e políticas de cada povo.

Percebe-se que após 1988 ocorreu toda uma transformação na educação escolar para os povos indígenas, a qual passa a dar lugar ao exercício da autonomia e expressão da sua identidade e, a partir do termo de interculturalidade, apresenta-se como espaço de contato entre mundos, formas e saberes distintos. Dessa forma, as identidades são reafirmadas ou interditadas, mediante as relações de poder e as resistências que emergem, e ressignificações e reinterpretações se estabelecem.

Mato Grosso (1997) aponta que a identidade está interligada a processos de convivência intercultural entre grupos sociais, sendo esse também um fator em que nos reconhecemos diferentes dos outros. 
Desse modo, é importante atentar para as abordagens relacionadas à revalorização cultural e histórica, no intuito de trazer reflexões sobre o respeito à identidade indígena e à sua história.

No contexto da educação escolar indígena em que se insere esta pesquisa, e que motivou a reflexão acerca dos processos de educação escolar desses povos indígenas, a identidade étnica é um fator fundamental. Pensar acerca de suas identidades étnicas pressupõe considerar a experiência de assumir-se como índio.

\section{EDUCAÇ̃̃O ESCOLAR INDÍGENA NO BRASIL E EM RORAMMA}

A educação escolar indígena passou por diferentes momentos históricos, sendo atribuídos variados significados, mediados pelo intento de implantar uma identidade nacional homogênea, acarretando o apagamento das identidades indígenas. Nesse sentido, conhecer esses processos históricos contribui para a análise da ação pedagógica atual adotada com os povos indígenas, de forma a possibilitar a reflexão sobre propostas pedagógicas democráticas que reafirmem e valorizem suas identidades.

Nesse sentido, como parte do pressuposto histórico, nota-se que a estruturação da educação indígena no Brasil teve início com a chegada dos jesuítas, sendo os dois primeiros séculos de colonização, de 1549 até 1756, marcados pela expulsão desses povos dos territórios portugueses. Esse momento é caracterizado como um período de dilaceração da cultura indígena, como estratégia de incorporar o índio à sociedade nacional como mão de obra. Do ponto de vista religioso, buscava-se a inserção de novos adeptos ao catolicismo, enquanto do ponto de vista econômico tornar o índio mais dócil facilitaria o objetivo de inseri-lo como mão de obra. Conforme menciona Ribeiro (2007, p. 23), “O plano legal (catequizar e instruir os índios) e o plano real se distanciam. Os instruídos serão descendentes dos colonizadores. Os indígenas serão apenas catequisados”.

Dessa maneira, percebe-se que a vinda dos portugueses ao Brasil com o intuito de expandir o sistema mercantil português, utilizando a mão de obra indígena nesse processo, coincidiu com a usurpação das terras dos indígenas, e as demais violências cometidas contra esses povos, que ocasionaram o extermínio de muitas etnias, seus conhecimentos tradicionais, seus modos próprios de viver e sua cultura. Abria-se então o caminho para o colonizador inserir novos hábitos que favorecessem a aceitação do que lhes era imposto, ação empreendida em especial por meio da educação.

O segundo período desse processo se estende de meados do século XVIII a meados do século XX, dividido em duas fases, sendo a primeira a fase Pombalina e a segunda, correspondente ao período que compreende o Império, a Primeira República e a ditadura Vargas. Na fase Pombalina, os jesuítas foram expulsos do Brasil e os aldeamentos, elevados à categoria de vila. Também foi criado o Diretório dos Índios, uma lei que impôs mudanças com cunho político-estratégico, com a abolição da escravidão indígena e uma série de medidas que visavam a inserção desses povos à sociedade colonial. Na verdade, era um meio de ocultar o verdadeiro intento, dando continuidade à expropriação e escravização dos indígenas por parte da sociedade colonial. Isso se evidencia nas medidas impostas, impondo às populações indígenas o pagamento de dízimos, assim como a proibição do uso de línguas indígenas em sala de aula e a obrigatoriedade da língua portuguesa, conforme menciona Farage (1991, p. 47):

Os índios que se recusaram terminantemente a trabalhar, querendo "viver a sua vontade", foram presos em grilhões e obrigados ao trabalho nas obras públicas; as mulheres, por sua vez, foram presas na cadeia pública, onde tinham por tarefa fiar algodão, de lá saindo apenas para a casa dos seus amos, a servirem na forma que devem.

Nas reflexões da autora, fica visível tamanha violência cometida contra as populações indígenas, embora fosse intitulada como uma liberdade formal no Diretório, quando na verdade se tratava de uma falsa liberdade, ou ficção política.

Em 1798, após a revogação do Diretório dos Índios, foi promulgado o Decreto 426, de 24 de julho, tratando das diretrizes gerais para a reintrodução dos missionários no Brasil, esses que vieram com a responsabilidade de catequisar e civilizar os índios. É importante frisar que, juntamente com o retorno dos missionários, deu-se também a reintrodução dos aldeamentos. Porém, diferentemente dos jesuítas, 
esses missionários agiram a serviço do governo brasileiro, prestando auxílio para a criação e manutenção de escolas destinadas a crianças e adultos indígenas que se interessassem em estudar, iniciativa inserida na política de desenvolvimento humano que buscava viabilizar a formação do povo brasileiro, o que, em relação aos indígenas, só seria alcançado mediante a sua catequização e inserção no trabalho (BRASIL, 2007).

Conforme abordagem anterior, verificou-se a continuação da estratégia política vigente, a questão econômica de inserir o índio como mão de obra na sociedade colonial, sem preocupações ou interesse em aspectos culturais e individuais da população indígena no Brasil, tendo apenas de modificar o meio de introduzi-la nesse sistema, diante da resistência desses povos ao domínio e à violência a que eram submetidos.

Conforme as reflexões de Ribeiro (2007), não ocorreram apenas mudanças econômicas e políticas no Brasil, influenciadas por essas, ocorreram também muitas transformações na educação. No entanto, surgiram diversos debates em relação à educação escolar primária organizada e mantida pelo poder público estatal com enfoque nas camadas mais baixas e menos visibilizadas da sociedade, sendo: negros, índios e mulheres. Isso se deu em meio tanto a um projeto nacional como um projeto internacional que definiam que a base do progresso moral, intelectual e social de qualquer país era determinada pela instrução do povo, favorecendo o investimento em escolas e alunos.

Mediante a instauração e consolidação do regime republicano, em 1910 foi criado o Serviço de Proteção aos Índios (SPI), com o intuito de integrar o índio à sociedade nacional por meio do trabalho. (BRASIL, 2007) Em relação à educação escolar:

Ela é posta como fundamental para a sobrevivência dos índios e inclui não só a leitura, mas também de outros conhecimentos como higiene, saneamento, estudos sociais, aritmética, ensinamentos práticos de técnicas agrícolas, marcenaria, mecânica e costura. A finalidade disso é fazer com que indígenas passem a atuar como produtores de bens de interesse comercial para o mercado regional e como consumidores das tecnologias produzidas pelos não-índios, constituindo também uma reserva alternativa de mão-de-obra barata pra abastecer o mercado de trabalho. (BRASIL, 2007, p. 13-14)

Conforme a citação anterior, verifica-se que o Estado até então continuava tanto com seu propósito de se apropriar das terras indígenas como de definir o índio como incapaz, necessitando de tutela por parte de um órgão indigenista a serviço de um governo que visava o progresso econômico do país, sem se preocupar com questões particulares e importantes das populações indígenas do Brasil. Em relação à educação escolar, percebe-se, conforme a citação, a preocupação em preparar o índio para o mercado de trabalho.

Outro acontecimento importante nesse período foi a implantação do programa de educação bilíngue nas escolas indígenas, visando a alfabetização do indígena tanto na sua língua materna como na língua portuguesa, contudo, passava a ter somente o ensino da língua portuguesa quando a dominava. (BRASIL, 2007). Portanto, percebe-se claramente que se tratava de uma estratégia de integração do índio à sociedade não índia, vindo a influenciar o índio ao abandono de seu modo de vida e sua identidade.

Esse projeto mostrava os mesmos propósitos dos governos anteriores: inserir e integrar o índio à sociedade nacional, mediante a educação, com o objetivo de transformá-lo em mão de obra para o Estado.

Conforme Ferreira (2001), aqui no Brasil essas manifestações se iniciaram nos anos 1970, quando uma série de organizações não governamentais passou a questionar o modelo educacional destinado às populações indígenas, e se desenvolveram experiências inovadoras com educação escolar voltada para as suas especificidades. Foi, portanto, a partir dessas experiências que surgiram propostas curriculares diferenciadas e materiais didáticos específicos para as escolas indígenas. Dinâmica que seria consagrada juridicamente com a Constituição Federal de 1988, abrindo caminhos para a criação e efetivação de políticas públicas em favor da manutenção de suas formas específicas de viver e de pensar, suas línguas, culturas e modos próprios de produção. E, em decorrência de todas essas manifestações, os Estados responderam através de diversos programas educativos: educação bilíngue e intercultural, educação intercultural e etnoeducação. 
As políticas públicas relativas à educação escolar indígena pós-constituição de 1988 passam a se pautar no respeito aos conhecimentos, às tradições e aos costumes de cada comunidade, tendo em vista a valorização e o fortalecimento das identidades étnicas. A responsabilidade pela definição dessas políticas públicas é atribuída, em 1991, ao Ministério da Educação. (BRASIL, 2007, p. 16)

Abordando essa temática de direitos conquistados mediante a Constituição, é importante citar outros documentos legais que regulamentam o direito dos povos indígenas a viver como índios, fortalecendo suas identidades e valorizando seus modos de viver e suas culturas. Após a Constituição de 1988, foram formulados documentos legais no plano educacional, em âmbito federal, como a Lei de Diretrizes e Bases da Educação Nacional (Lei n 9.394/96), o Plano Nacional de Educação (Lei nº 10.172, de 9 de janeiro de 2001) e o Parecer n ${ }^{\circ}$ 14/99 do Conselho Nacional de Educação (CNE), que trata das diretrizes curriculares nacionais para a educação nas escolas indígenas, regulamentado pela Resolução CNE n 03/99, conforme demonstrado no Congresso Nacional de Educação (FERREIRA, PRADO, 2013).

Conforme a abordagem anterior sobre o Referencial Curricular Nacional para Escolas Indígenas (BRASIL, 1998), verificou-se que essa legislação contempla a heterogeneidade e as vivências dos povos indígenas do Brasil em suas diversas especificidades e particularidades, privilegiando seus conhecimentos e saberes milenares no processo de ensino e aprendizagem nas escolas.

Em relação à Lei de Diretrizes e Bases da Educação Nacional, no quesito Educação Escolar Indígena, aponta como dever do Estado o oferecimento de uma educação intercultural e bilíngue, favorecendo as práticas socioculturais e o uso da língua materna, assim como o fortalecimento das identidades dos povos indígenas do Brasil, conforme determina em seus artigos (BRASIL, 1996).

Roraima, em suas características gerais, reforça essa trajetória da educação escolar indígena no Brasil. O estado situa-se na região Norte do Brasil, fazendo fronteira com a Venezuela, ao Norte, e com a República Cooperativista da Guyana, a Nordeste. É um estado com uma grande diversidade cultural, constituído pelos povos indígenas Makuxi, Patamona, Pemon, Wai Wai, Ingaricó, Taurepang e Wapichana e por migrantes de vários estados do Brasil, principalmente do Nordeste e da própria região amazônica.

Os povos indígenas abordados nesta pesquisa, Makuxi e Wapichana, considerados antigos habitantes da região amazônica, pertencem ao "tronco linguístico karíb (Makuxi, Patamona, Pemon, Wai Wai, Ingaricó, Taurepang, entre outros) e arawak (Wapichana, Atorai, entre outros)” (OLIVEIRA, 2011, p. 23). Conforme estimativa do Instituto SocioAmbiental (2018), o povo Makuxi constitui uma população de 33.603 mil índios no Brasil e 9.500 mil índios na Guyana, ocupando a Terra Indígena Raposa Serra do Sol, a Terra Indígena São Marcos e pequenas áreas que circunscrevem aldeias isoladas no extremo Noroeste, nos vales dos rios Uraricoera, Amajari e Cauamé. Já o povo Wapichana se encontra disperso ao Norte, a Leste e a Oeste da capital de Roraima, totalizando 140 comunidades indígenas no Brasil e 50 na Guyana.

A educação escolar indígena em Roraima foi construída a partir das lutas do movimento indígena, que, aliado à Igreja Católica, reivindicava um modelo de educação escolar que atendesse às especificidades das comunidades indígenas, conforme abordagem de Nascimento (2014, p. 93):

Em Roraima, as primeiras escolas que se tem notícia [...] forma instaladas em um primeiro momento pelos Beneditinos, que chegaram à região no ano de 1909 e aí permaneceram até o ano de 1947, e posteriormente pelo Serviço de proteção aos índios (SPI) que neste período também se instalou na região.

O autor aborda a trajetória da educação no Brasil e afirma que a filosofia da Igreja Católica estava vinculada ao ensino da língua portuguesa e ao processo de civilização. Enquanto o Serviço de Proteção aos Índios tinha como objetivo a formação profissional e nacionalista, com o intuito de adentrar as terras indígenas do Brasil, inserido em um projeto capitalista. Assim, percebe-se que nenhum dos dois projetos prezavam a valorização das culturas e reafirmação das identidades indígenas, emergindo mais como dizimadores da cultura do índio.

A partir da década de 1970, influenciados pelo movimento indígena, Tuxauas e lideranças indígenas passaram a reivindicar uma educação escolar indígena que privilegiasse questões culturais, principalmente 
o direito de falar a língua materna, assim como a substituição de professores não indígenas por indígenas. Tal reivindicação culminou em um importante momento histórico, no ano de 1985, denominado “Dia D”, em que ocorreu uma grande mobilização em nível federal, da qual os educadores de Roraima puderam participar, reivindicando um currículo específico e diferenciado que respeitasse as identidades étnicas dos povos indígenas. Em decorrência desse "Dia D”, em 1986, foi criado o NEI - Núcleo de Educação Indígena, ligado à Secretaria de Educação, objetivando acompanhar as atividades relacionadas à educação escolar indígena, conforme menciona Repetto (2002).

Outro marco importante na educação escolar indígena em Roraima foi a criação da Organização dos Professores Indígenas de Roraima (OPIRR), em 1990, após um encontro de professores indígenas de todo o Estado, realizado na Missão Surumu. Em consonância com suas reivindicações, em 1994, na Secretaria de Educação, foi criado o Projeto de Magistério Indígena, visando a formação de professores indígenas no Estado. Ainda diante de tais reivindicações sobre a formação de professores, em 2001, foi elaborado um documento denominado Carta de Canauanim, em que lideranças e professores reclamavam uma formação superior para os professores indígenas, culminando na criação da Licenciatura Intercultural, na Universidade Federal de Roraima, com a sua primeira turma em 2003. (NASCIMENTO, 2014)

Após tantos anos de lutas e reivindicações, os povos indígenas de Roraima dispõem de uma educação escolar indígena específica e diferenciada, bilíngue e intercultural. E permanece a associação dos professores indígenas até os dias atuais, discutindo e formulando questões referentes à educação escolar indígena e todos os seus processos, desde a prática pedagógica até a formação de professores e a participação em esferas de poder do Estado. A educação escolar indígena de Roraima é organizada pela Divisão de Educação Escolar Indígena (DIEI), que gerencia as 248 escolas no estado, sendo parte da estrutura da Secretaria de Educação, com o apoio dos Centros Regionais de educação localizados nas terras indígenas do estado. (NASCIMENTO, 2014)

Frente a tais abordagens, verifica-se que a história da educação escolar indígena no estado é de lutas, conquistas e desafios. E, como resultado, as comunidades indígenas do estado dispõem de educação diferenciada bilíngue e intercultural.

A partir da fundamentação desses documentos apresentados, e de toda a trajetória histórica da educação indígena no Brasil e em Roraima, cabe destacar que, para se compreender a educação escolar indígena, é de suma importância considerar que após 1988 os povos indígenas puderam refletir sobre o tipo de educação escolar que cada povo deseja, com a elaboração de currículos próprios e diferenciados que condizem com a realidade, bem como a capacitação e formação de professores indígenas.

\section{IDENTIDADE ÉTNICA E EDUCACÃO ESCOLAR INDÍGENA}

A educação escolar indígena, através dos amparos jurídicos, presume uma educação diferenciada, com políticas públicas que respondam aos seus direitos educacionais, sendo intercultural e bilíngue, de modo a atender a autodeterminação dos seus povos. Portanto, exige a valorização da identidade étnico-cultural do indígena, na tarefa de se assumir como sujeito social, político, cultural e histórico.

Este processo de estruturação de uma escola indígena passa pela compreensão de que a educação escolar indígena deve estar orientada a socialização das crianças, sem interferir nos processos de socialização estabelecidos pela comunidade. (MATO GROSSO, 1997, p. 185)

Com base em Hall (1999), compreende-se o papel fundamental da escola como sistematizadora dos conhecimentos socialmente construídos. Por isso é importante a abordagem sobre a história dos povos indígenas no Brasil, sua cultura e, por conseguinte, o respeito à identidade indígena.

De acordo com Freire (2009, p. 26),

Pensar em índios frequentando a escola criada por e para "brancos” é um problema que ainda não vem sendo evidenciado nas reivindicações das diferentes etnias, uma vez que a preocupação manifesta pelos movimentos indígenas organizados é com a criação e manutenção de escolas que atendam as diferentes culturas em espaços culturais de cada etnia. 
Dessa maneira, entra em questão a elaboração de um currículo específico e diferenciado, levando em consideração todas as vivências, os saberes e os conhecimentos da comunidade, abordando a experiência e a realidade dos povos indígenas. E assim também surge a necessidade de compreensão do movimento interno das culturas e a sua relação com a sociedade.

[...] em que é imprescindível entendimento, rigorosidade e criticidade com os conceitos e as teorias para a compreensão das culturas, de suas dinâmicas internas e das relações de uma para com outra. Isso, numa perspectiva crítica, para que a ação pedagógica possa ser libertadora e não reproduza teorias colonizadoras que esmagam culturas. (FREIRE, 2004, p. 71)

Faz-se necessário então pensar numa escola que seja pautada pela sua realidade, suas especificidades, valorizando seus costumes, tradições, língua, pensamentos e práticas socialmente compartilhadas, até se inserir no conhecimento da cultura que permeia a sua, seja ela regional, nacional ou mundial. Dessa forma, “[...] A perda cultural não virá da simples escolarização, mas virá como resultado das práticas de escolarização acríticas, as políticas e que não partam do reconhecimento, reflexão e valorização da própria cultura” (MATO GROSSO, 1997, p. 185).

Nesse mesmo contexto, a língua é um fator primordial no quesito valorização da história e identidade desses povos, levando em consideração a proposta curricular das escolas indígenas, e tendo em vista que a identidade é um elemento importante no que se refere à convivência intercultural, reafirmando a identidade pessoal e o compromisso social dos indivíduos, sendo capazes de contribuir seus saberes, conhecimentos e experiências, vindo a formular uma identidade grupal, conforme afirma Burbano Paredes (1994).

Então, deve-se trabalhar no currículo da escola indígena bilíngue e intercultural questões sobre a identidade indígena, bem como atentar para o que está sendo construído nessa interação de ambas, visando a legitimação dos conhecimentos indígenas e o respeito à escolarização. (MATO GROSSO, 1997)

Em relação a essas construções que se referem às distinções e desigualdades entre os sujeitos, Louro (1997, p. 65) aborda que:

\footnotetext{
Os questionamentos em torno desses campos, no entanto, precisam ir além das perguntas ingênuas e dicotomizadas. Dispostas/os a implodir a ideia de um binarismo rígido nas relações de gênero teremos de ser capazes de um olhar mais aberto, de uma problematização mais ampla (e também mais complexa), uma problematização que terá de lidar, necessariamente, com as múltiplas e complicadas combinações de gênero, sexualidade, classe, raça, etnia. Se essas dimensões estão presentes em todos os arranjos escolares, se estamos nós próprias/os envolvidas/os nesses arranjos, não há como negar que essa é uma tarefa difícil.
}

Dessa maneira, ao se pensar nessas apropriações por parte de professores(as) e alunos(as), percebe-se a escola como um local de cidadania, levando em consideração quais questionamentos são produzidos em relação aos sujeitos nela envolvidos, percebendo as relações de poder, os preconceitos e as diferenças entre eles. Isso pode contribuir para dar visibilidade a essas minorias, e através disso promove-se a libertação da forma padronizada como concebemos nossa relação com o outro e a análise sobre as identidades indígenas no ambiente escolar.

\section{RELATO DE EXPERIÊNCIA: OS REFLEXOS DO ESPELHO}

Durante discussões em um encontro de professores indígenas na região da Serra da Lua, município de Cantá, estado de Roraima, para debater a respeito de práticas pedagógicas e questões gerais sobre a educação escolar indígena, um professor relatou que havia perguntado aos seus alunos se já haviam visto índios, e todos responderam que não. Então, o professor pediu que todos se olhassem no espelho e contassem no outro dia em sala se conseguiram ver um índio. No outro dia os alunos relataram que não haviam visto nenhum índio, somente um aluno disse que havia visto um índio correndo com a sua flecha.

Instigada com tal relato, resolvi fazer uma atividade similar à que o professor havia descrito no encontro de professores. E então perguntei a todos(as) os(as) alunos(as) da escola, entre crianças e adolescentes das turmas do primeiro ano ao nono ano do Ensino Fundamental, se já tinham visto um "índio". A 
resposta foi uma surpresa, pois a maioria respondeu que nunca havia visto índios pessoalmente, somente em jornais, revistas e livros.

A atividade foi realizada por turma, uma de cada vez. Após a pergunta dirigida à turma, solicitei a todos(as) que fossem olhar a imagem de um índio no meu celular, um de cada vez, e depois não poderiam falar nada aos(às) colegas. No celular estava acionada a câmera no modo selfie. Quando olhavam a própria imagem no aparelho, sorriam. Ao final da atividade, expliquei que os índios a que me referia éramos todos nós, desde os(as) professores(as) aos(às) alunos(as), sendo pertencentes às etnias Makuxi e Wapichana, reforçando a identidade étnica de todos(as).

Diante dessa postura do(a) aluno(a) de não se assumir como indígena em sala de aula, resta um vazio, que necessita ser pensado. Daí vem a necessidade de o(a) professor(a) abordar em sala de aula os processos culturais e históricos dos povos indígenas do Brasil e de Roraima, levando os(as) alunos(as) a repensar e entender melhor os significados e a trajetória histórica da identidade indígena, sabendo que o índio não é somente aquele que está no livro pintado com cocar, e sim o(a) aluno(a) que usa roupas, calça sapatos e possui celular, de forma a incentivá-lo(la) a se assumir como tal. Nessa perspectiva, evidenciar que o indígena não é só esse ser que os livros didáticos abordam, usando um cocar e com pinturas corporais, mas também indivíduos que moram tanto na comunidade indígena como na cidade, possuem transporte, usam roupas e têm aparelhos eletrônicos.

As respostas fazem emergir de imediato um sentimento de responsabilidade enquanto docente, bem como a consciência da necessidade de promover um ensino de qualidade voltado para a realidade de cada aluno(a), levando em conta níveis de compreensão e experiência pedagógica, agindo como mediador(a) no processo de ensino e aprendizagem.

A eficácia no processo de reafirmação de identidades está atrelada a um planejamento que privilegie a valorização da cultura, das qualidades e dos valores dos(a) alunos(as), conduzindo-os(as) a uma posição transformadora, que os(as) habilite a promover as ações coletivas e o viver em sociedade.

Considerando a reflexão de que o ensino e a aprendizagem ocorrem mediante a relação entre professor e aluno, e analisando a questão da abordagem sobre as identidades étnicas, verifica-se a necessidade da busca de conhecimento referente a esse tema por parte dos(as) professores(as), levando em consideração o currículo descrito das escolas indígenas, que devem promover uma educação bilíngue, específica e diferenciada capaz de valorizar a cultura e os modos de viver, pensar e agir dos povos indígenas.

Compreende-se que o não reconhecimento dos discentes Makuxi e Wapichana em relação à identidade indígena e o sentimento de vazio por não se estar contribuindo para a formação da identidade indígena vão além da prática docente. A modalidade de relato de experiência, entretanto, não permite uma pesquisa mais aprofundada, mas provoca algumas reflexões que poderão auxiliar a problematização do fazer educação durante o período pós-consolidação da educação escolar indígena.

A primeira reflexão diz respeito ao estágio da compreensão de tempo e espaço dos(as) discentes, haja vista que ainda está se estabelecendo de forma processual a apreensão da realidade em que vivem. De acordo com Ferreira e Marques (2012, p. 233),

É sempre importante lembrar que o tempo, enquanto abstração teórica, só existe e pode ser significado sua relação com algum referencial. O referencial principal a ser considerado no ambiente escolar deve ser sempre o aluno, seu tempo, seu contexto, isso antes de qualquer proposição didática sobre qualquer noções aprendidas.

Partindo da perspectiva de que o(a) adolescente ainda está passando por estágio de apreensão da realidade em que vive, ou seja, ainda está ocorrendo a abstração do tempo presente, do passado e do seu lugar social, a identidade dentro da perspectiva histórica também está sendo aprendida processualmente. Essa aprendizagem, segundo Ferreira e Marque (2012), poderá ocorrer de forma significativa a partir das próprias histórias dos(as) alunos(as).

A segunda reflexão se refere ao lugar de construção da identidade - o processo de afirmação ou negação da identidade envolve também lugares de conflitos, de disputas. Silva (2007, p. 82) esclarece que "A afirmação da identidade significa demarcar fronteiras, significa fazer distinções entre o que fica dentro e o que fica fora. A identidade está sempre ligada a uma forte separação entre 'nós e eles’ [...]”. 
Considerando que os(as) discentes em estudo vivem na comunidade e estudam em instituição escolar indígena, a experiência de ser índio não é uma forte demarcação, uma questão que sintam necessidade de afirmar ou negar nas relações com as outras etnias do cotidiano escolar. É um espaço de aparentes iguais, não há necessidade de afirmar ou negar que é indígena, apesar da consciência das especificidades de cada etnia. Embora também envolva relações de poder, é distinto quando comparado ao cotidiano de escolas não indígenas na cidade, onde a necessidade de afirmação ou negação da identidade indígena ocorria de forma mais frequente e ainda acontece em determinadas situações.

A terceira reflexão possível diz respeito ao processo de construção social, cultural e dinâmica da identidade. Tomando de empréstimo a célebre frase de Simone Beauvoir, "Não se nasce mulher, torna-se mulher”, nessa óptica, não se nasce índio, torna-se índio. Assim como não se nasce índia, torna-se índia. Nesse aspecto, acrescenta-se a categoria gênero, compreendida como "um elemento construtivo de relações sociais fundadas entre as diferenças percebidas entre os sexos", vistas como construções sociais, culturais, dinâmicas e históricas. (SCOTT, 1996, p. 21)

Nesse sentido, aprende-se a ser índio(a) por meio dos significados atribuídos a cada um no cotidiano da comunidade, na escola, nas relações com outras etnias e fora delas. Na interação desenvolvida nas atividades culturais - a exemplo da dança do parixara e do prazer de comer damorida, no caso de Roraima -, nas reivindicações pelo direito às terras indígenas e a uma educação intercultural, enfim, nas várias representações e significados de ser índio(a) de sujeitos femininos e masculinos construídos ao longo da história, nas comunidades e fora delas, de forma negativa ou afirmativa, nota-se a existência de diferentes espaços que também revelam relações de poder.

Desse modo, pode-se constatar que as representações étnicas tanto dos(as) discentes como dos(as) docentes são construções históricas, e não naturais. Conforme Hall (1999, p. 13), a identidade "torna-se uma 'celebração móvel' formada e transformada continuamente em relação às formas pelas quais somos representados ou interpelados nos sistemas culturais que nos rodeiam”. Portanto, a identidade étnica, vista enquanto identidade cultural, perpassa por processos de ressignificação provocados por várias experiências compartilhadas no mundo contemporâneo e do passado - conforme se defende neste estudo, provocados por meio da assimilação de histórias e tradições dos povos indígenas, como também de várias redes de saberes referentes às culturas dos povos indígenas e não indígenas.

Santos (2016, p. 105), ao estudar a identidade étnica Wapichana, observa que:

A cultura envolve coletividade e ao falar em coletividade não tenho a pretensão em pensá-la como estável, pronta e acabada, muito pelo contrário, só dá indicativos para constantes reelaborações [...] que reflete em um elemento chave a identidade.

Destarte, o processo de construção da identidade passa pela experiência e pela reelaboração de conceitos de si e da cultura, os quais são construções sociais, culturais e históricas vivenciadas individualmente e coletivamente de forma dinâmica.

A quarta questão se refere aos deslocamentos que essas reflexões podem provocar, no sentido de ampliar olhares e encorajar a problematização de outras identidades culturais ainda silenciadas em parte das produções dentro da temática indígena, como a das mulheres indígenas. Embora não tenham sido focalizadas neste trabalho, elas fazem parte desse processo de afirmação da identidade étnica, seja na escola, na comunidade e ou fora dela, por meio da participação nas organizações indígenas, a exemplo da Organização da Mulheres Indígenas (OMIR). Portanto, de forma direta ou indireta, elas tecem um tipo específico de mulheres quando questionam as relações desiguais, denunciam a violência contra a mulher indígena ou quando encorajam as filhas a conquistar seus espaços. São indícios de mudanças nas relações de gênero em direção a relações mais iguais. Assim sendo, o movimento de afirmação das identidades também deve levar em consideração a negociação de diferentes sujeitos, que passam a reivindicar espaços e reconhecimentos.

Tal movimento de conquistas, resistência e permanência da educação escolar indígena hoje mostra resultados e suscita alguns deslocamentos, que envolvem outras subjetividades acerca das identidades indígenas na comunidade escolar, demandando também outro perfil de docentes, mais sensíveis às mudanças e com saberes teóricos e metodológicos que sejam capazes de gerar uma sintonia entre as gerações 
de forma horizontal. Que proporcionem a revisitação da cultura, articulada com novos conhecimentos técnicos, teóricos, metodológicos e assimilada em suas comunidades, em instituições de formação intercultural, a exemplo do Instituto Insikiran de Formação Superior Indígena da Universidade Federal de Roraima, somando-se a outras produções de pesquisadores(as) indígenas e não indígenas sobre a educação intercultural.

Assim, acredita-se que ampliar a leitura acerca do fazer educação na perspectiva das diferenças e das identidades culturais possibilitará problematizar e descortinar outras questões e sujeitos silenciados que, de forma direta ou indireta, já apresentam inquietações acerca das normatividades que envolvem uma identidade unificada, bem como novas subjetividades de ser indígena e fazer educação intercultural no século XXI. Portanto, o reflexo do espelho também sinaliza a necessidade de reinventar a identidade docente nesta fase de consolidação da educação escolar indígena e de velocidade de informação em múltiplos veículos.

\section{CONSIDERAÇÕES FINAIS}

Considera-se importante a compreensão da trajetória histórica da educação indígena no país, levando em conta que os indígenas eram vistos como primitivos e incapazes, necessitando da tutela do Estado, e não tinham sua cultura e suas especificidades respeitadas. A Constituição de 1988, no entanto, trouxe um novo olhar sobre a questão indígena, com seus direitos garantidos e implementados.

Dessa maneira, faz-se necessário refletir sobre a criação de práticas pedagógicas que promovam a libertação e valorização das culturas desses povos, como forma de reafirmar as identidades dos alunos indígenas.

A identidade étnica que permeia a escola estadual indígena no estado de Roraima é vinculada a estereótipos criados sobre os índios, desde o período da colonização pelos europeus, como também a toda a trajetória histórica dos povos indígenas, que não tiveram direito de escolher viver com suas culturas, perdendo a identidade ao serem obrigados a fazer uso de elementos culturais dos não indígenas envolvidos nesse processo de colonização. Essa realidade se reflete na escola e na sociedade nos dias atuais, mediante a visão de que o indígena é aquele que vive na floresta, ou aquele que estava aqui quando os portugueses chegaram.

Observou-se que isso acontece porque os livros e materiais didáticos utilizados nas escolas indígenas apresentam um "índio" estereotipado. O que se destaca é a figura de um indígena exibindo pinturas corporais, vestindo trajes tradicionais e vivendo em casa coberta de palha, não coincidindo com a realidade deles, que usam roupas, possuem aparelhos eletrônicos e moram em residência coberta de telhas.

Nesse sentido, cabe aos docentes atentar para isso e fazer com que os alunos se percebam e possam se identificar como indígenas, mostrando que, mesmo que não sejam da forma como os materiais didáticos apresentam, continuam a ser indígenas. Esse povos não integraram a sociedade no passado, mas hoje a afirmação da identidade, da cultura e a educação escolar indígena são direitos assegurados na Constituição de 1988, assim como a participação em diferentes espaços da sociedade brasileira e roraimense.

Diante disso, fica evidente a responsabilidade e o compromisso da escola e dos docentes na elaboração e execução de propostas curriculares numa perspectiva de educação intercultural, que privilegiem as especificidades culturais, a identidade étnica, mas não só, também provoquem reflexões a respeito das gerações e de gênero, por exemplo, ou seja, diferentes subjetividades silenciadas que apontam outras reflexões, visando uma educação escolar indígena mais inclusiva.

É necessária uma reflexão acerca do quão profunda e fértil é a problemática da educação escolar indígena, de modo que, a partir dessas reflexões, possam ocorrer mudanças sobre as questões culturais e a educação indígena do estado de Roraima. 


\section{REFERÊNCIAS}

BRASIL. Casa Civil. Subchefia para Assuntos Jurídicos. Lei no 9.394, de 20 de dezembro de 1996. Estabelece as diretrizes e bases da educação nacional. Disponível em: <http:/www.planalto.gov.br/ ccivil_03/leis/19394.htm>. Acesso em: 24/06/2018.

BRASIL. Ministério da Educação. Referencial Curricular Nacional para as Escolas Indígenas. Brasília: SEF/MEC, 1998.

BRASIL. Ministério da Educação. Secretaria de Educação Continuada, Alfabetização e Diversidade. Educação escolar indígena: diversidade sociocultural indígena ressignificando a escola. Cadernos SECAD. Brasília-DF, $\mathbf{n}^{\circ}$. 3, abril 2007. Disponível em: <http://portalmec.gov.br/secad/arquivos/pdf/ educacaoindigena.pdf $>$. Acesso em: 24/06/2018.

BURBANO PAREDES, J. B. Docência bilíngue intercultural. Uma especialização para nuestros dias. Quito: Abya-yala, 1994.

FARAGE, N. As muralhas dos sertões: os povos indígenas no Rio Branco e a colonização. Rio de Janeiro: Paz e Terra; ANPOCS, 1991.

FERREIRA, A.; PRADO, M. G. Um novo olhar à educação indígena a partir da Constituição de 1998. Anais do XI Congresso Nacional de Educação EDUCERE. Curitiba, Pontifícia Universidade Católica do Paraná, 2013.

FERREIRA, C. A. L.; MARQUES, E. S. Espaço e tempo como dimensões do conhecimento e objeto de ensino-aprendizagem em história. História Hoje. São Paulo, v, 1, nº. 2, p. 227-246, 2012.

FERREIRA, M. K. L. A educação escolar indígena: um diagnóstico crítico da situação no Brasil. In: SILVA, A.L.; FERREIRA, Mariana K. L. (Orgs.). Antropologia, história e educação: a questão indígena e a escola. 2a . ed. São Paulo: Global, 2001.

FREIRE, J. R. B. Trajetória de muitas perdas e poucos ganhos. In: IBASE. Educação escolar indígena em terra brasilis: tempo de novo descobrimento. Rio de Janeiro: IBASE, 2004.

FREIRE, M. C. B. A criança indígena na escola urbana. Manaus: Editora da Universidade Federal do Amazonas, 2009.

HALL, S. A identidade cultural na pós-modernidade. Rio de Janeiro: DP\&A, 1999.

INSTITUTO SOCIOAMBIENTAL. Povos indígenas no Brasil. Macuxi. 19 jul. 2018. Disponível em: $<$ https://pib.socioambiental.org/pt/Povo:Macuxi>. Acesso em: 26 maio 2020.

LOURO, G. L. Gênero, sexualidade e educação: uma perspectiva pós-estruturalista. Petrópolis, RJ: Vozes, 1997.

MATO GROSSO. Secretaria de Estado de Educação. Conselho de Educação Escolar Indígena de Mato Grosso. Urucum, jenipapo e giz: a educação escolar indígena em debate. Cuiabá: Entrelinhas, 1997.

NASCIMENTO, R. N. F. Interculturalidade e educação escolar indígena em Roraima: da normatização à prática cotidiana. Tese (Doutorado em Antropologia), Programa de Pós-Graduação em Antropologia da Universidade Federal de Pernambuco, Recife, 2014.

OLIVEIRA, R. G. O Rio Branco no contexto da Amazônia Caribenha: aspectos da colonização europeia entre o século XVI e XVIII. In: MARTINS, E. C. R.; MOREIRA, F. K. (Orgs.). As relações internacionais na fronteira norte do Brasil: coletânea de estudos. Boa Vista: EDUFRR, 2011.

REPETTO, M. Roteiro de uma etnografia colaborativa: as organizações indígenas e a construção de uma educação diferenciado em Roraima, Brasil. Tese (Doutorado em Antropologia), Universidade de Brasília, Brasília, 2002.

RIBEIRO, M. L. S. História da educação brasileira: a organização escolar. 20ª ed. São Paulo: Autores Associados, 2007. 
SANTOS, L.P. “Nós somos Wapichana”: educação, política e protagonismo indígena (1979-2014). Dissertação (Mestrado em História), Universidade Federal do Amazonas, Manaus, 2016.

SCOTT, J. W. Gênero: uma categoria de análise histórica. 3ª ed. Recife: SOS Corpo, 1996.

SILVA, T. T. A produção social da identidade e diferença. In: SILVA, Tomaz Tadeu da (Org.). Identidade e diferença: a perspectiva dos estudos culturais. 7ª ed. Petrópolis, RJ: Vozes, 2007. 